\title{
Malfunction of Totally Implantable Central Venous Ports
}

\author{
Hyo-Cheol Kim,, ${ }^{1,}$ Saebeom Hur, ${ }^{1}$ and Hoyong Jeon ${ }^{1}$ \\ ${ }^{1}$ Department of Radiology, Seoul National University Hospital, Seoul, Korea \\ "Corresponding author: Hyo-Cheol Kim, Department of Radiology, Seoul National University Hospital, Seoul, Korea. Tel: 82-220722584, Fax: 82-27437418, E-mail: \\ angiointervention@gmail.com
}

Received 2014 July 15; Revised 2014 November 08; Accepted 2015 January 09.

\begin{abstract}
Background: Malfunctions of totally implantable central venous ports (TICVPs) have become a problem, as the usage of TICVPs has increased enormously.

Objectives: This study evaluated factors related with catheter malfunctions of TICVPs.

Patients and Methods: Between January 2010 and June 2012, 1,740 TICVPs in 1740 patients (874 men and 866 women) with an average age of $57.7 \pm 12.8$ years (range: 15 - 91 years) were implanted by an interventional radiology team at our institute. Catheter malfunctions were retrospectively analyzed. In the prospective study, we randomly allocated 176 patients to two kinds of TICVPs in a 1:1 assignment ratio. The primary outcome was the malfunction of TICVPs.

Results: In the retrospective study, the 32 malfunctioning TICVPs were caused by fibrin sheath formations $(\mathrm{n}=15)$, chamber thrombosis $(n=8)$, TICVP rotation ( $n=5)$, catheter migration $(n=2)$, and blood clots within the catheters $(n=2)$. Multivariate analysis showed that being female was a significant factor for poor patency rates of TICVPs (hazard ratio: 5.06; 95\% confidence interval (CI) $1.32-19.46, P=0.018)$. In the prospective study, two chamber thromboses occurred in Celsite $(n=1)$ and Humanport $(n=1)$. The primary patency rates of both Celsite $₫$ and Humanport $®$ were $98.9 \%$ at 6 months, respectively.

Conclusion: Our data suggest that catheter malfunctions of TICVPs are more common in females than males. The incidence of TICVP malfunctions does not differ between the two devices (Celsite $\mathbb{B}$ vs. Humanport $₫$ ).
\end{abstract}

Keywords: Central Venous Access, Totally Implantable Central Venous Port, Malfunction

\section{Background}

The insertion of subcutaneous totally implantable central venous ports (TICVPs) is a common procedure in cancer patients requiring chemotherapy. The need for a TICVP insertion has dramatically increased over the last few decades in parallel with the various intravenous chemotherapeutic agents used in cancer patients. Various types of TICVPs are currently implanted by way of several techniques and venous access by vascular surgeons, interventional radiologists, and oncologists (1-6).

Interventional radiologists mostly prefer the internal jugular vein as a venous access site under ultrasonic and fluoroscopic guidance (4-7). The ultrasound guided puncture of veins and fluoroscopic positioning of the catheter tip result in safe implantation procedures and a reduction in immediate complications that may include pneumothorax, arterial puncture, and hematoma formation (47). However, the malfunction of TICVPs (inability to infuse and/or the regurgitation of fluid) is still an important factor that interrupts the use of the device (8). The reasons for TICVP malfunctions include catheter thrombosis, fibrin sheath formation around the catheter, kinking or migration of the catheter, and port rotation. However, factors influencing the malfunction of TICVPs have not been exten- sively investigated.

\section{Objectives}

In this retrospective study, we aimed to retrospectively analyze the incidences and causes of TICVP malfunctions in 1,740 patients. In the prospective study, we aimed to perform a prospective randomized trial for the comparison of two devices available in Korea.

\section{Patients and Methods}

\subsection{Study Populations}

Between January 2010 and June 2012, 1740 TICVPs in 1740 patients ( 874 men and 866 women) with an average age of $57.7 \pm 12.8$ years (range: 15 - 91 years) received implants by an interventional radiology team at our institute. Demographic data and underlying diseases are shown in Table 1. In all patients, TICVP placement was indicated for the administration of intravenous chemotherapy. We used two kinds of TICVP systems: Celsite $®$ (9.6 Fr, B. Braun Medical, Boulogne, France) and Humanport $₫(8 \mathrm{Fr}$, Insung Medical, Seoul, Korea). Institutional review board approval was obtained for this study. 


\begin{tabular}{|c|c|c|}
\hline Patient Characteristics & Retrospective Study $(n=1,740)$ & Prospective Study $(n=176)$ \\
\hline Age, $y$ (range) & $57.7(15-91)$ & $57.0(20-79)$ \\
\hline \multicolumn{3}{|l|}{ Sex } \\
\hline Men & $874(50.2)$ & $93(52.8)$ \\
\hline Women & $866(48.8)$ & $83(47.2)$ \\
\hline \multicolumn{3}{|l|}{ Underlying disease } \\
\hline Colorectal cancer & $892(51.3)$ & $93(52.8)$ \\
\hline Gastric cancer & $242(13.9)$ & $12(6.8)$ \\
\hline Breast cancer & $166(9.5)$ & $13(7.4)$ \\
\hline Lymphoma & $163(9.4)$ & $33(18.8)$ \\
\hline Sarcoma & $53(3.0)$ & $7(4)$ \\
\hline Pancreatic cancer & $45(2.6)$ & $7(4)$ \\
\hline Ovarian cancer & $39(2.2)$ & $2(1.1)$ \\
\hline Lung cancer & $31(1.8)$ & $1(0.6)$ \\
\hline Cholangiocarcinoma & $23(1.3)$ & $2(1.1)$ \\
\hline Cervical cancer & $14(0.8)$ & $2(1.1)$ \\
\hline Other solid tumors & $72(4.1)$ & $4(2.3)$ \\
\hline \multicolumn{3}{|l|}{ Access site } \\
\hline Right internal jugular vein & $1,643(94.4)$ & $172(97.7)$ \\
\hline Left internal jugular vein & $97(5.6)$ & $4(2.3)$ \\
\hline \multicolumn{3}{|l|}{ Port } \\
\hline Celsite & $864(49.7)$ & $87(49.4)$ \\
\hline Humanport & $876(50.3)$ & $89(50.6)$ \\
\hline
\end{tabular}

${ }^{\mathrm{a}}$ Values are expressed as No. (\%).

Between November 2012 and February 2013, 176 TICVPs in 176 patients ( 93 men and 83 women) with an average age of 57.0 years (range: 20 - 79 years) were implanted at our institute. We randomly assigned patients in a 1:1 ratio following simple randomization procedures (computerized random numbers) to two types of TICVP systems including Celsite $(9.6 \mathrm{Fr}$, B. Braun Medical) and Humanport $®(8 \mathrm{Fr}$, Insung Medical) (Table 1). Exclusion criteria were as follows: bacteremia; local infection at the port implantation site; uncorrectable coagulopathy with a platelet count $<50 / \mathrm{nL}$, PTT $<50 \%$, and INR $>1.5$; and acute venous thrombosis or chronic complete obstruction at the internal jugular vein or superior vena cava. Demographic data and underlying diseases are shown in Table 2. Institutional review board approval was obtained for this study, and the trial was registered at ClinicalTrials.gov (NCT01733342).

\subsection{Procedures}

Written informed consent was obtained from each patient prior to performing the procedure. The clinician determined the use of prophylactic antibiotics considering the patient's general condition or absolute neutrophil count. The common access route was the right internal jugular vein in most patients. However, the left internal jugular vein was chosen in selected patients who had undergone a right mastectomy due to breast cancer or had radiation therapy in the right chest area.

After a local infiltration of 1\% lidocaine (Dong-A Pharmaceutical, Korea, Seoul), the jugular vein was punctured using a 21-gauge needle under ultrasound guidance and a micropuncture introducer set (Cook, Bloomington, Indiana) was advanced over a 0.018-inch guidewire. Then, a 0.035-inch guidewire was exchanged into a 5-French introducer set. Thereafter, the port reservoir pocket was created in a subcutaneous layer of the anterior chest wall. The port catheter was tunneled from the pocket to the punc- 
Table 2. Characteristics According to the TICVP Type

\begin{tabular}{|c|c|c|c|c|c|c|c|c|}
\hline \multirow{2}{*}{$\begin{array}{l}\text { Patient } \\
\text { characteristics }\end{array}$} & \multicolumn{4}{|c|}{ Retrospective Study } & \multicolumn{4}{|c|}{ Prospective Study } \\
\hline & $\begin{array}{c}\text { Overall }(\mathbf{n}= \\
1,740)\end{array}$ & Celsite $(n=864)$ & $\begin{array}{l}\text { Human port ( } \mathrm{n} \\
=876)\end{array}$ & P Value & Overall $(n=176)$ & Celsite $(n=87)$ & $\begin{array}{l}\text { Human port }(\mathbf{n} \\
=89)\end{array}$ & P Value \\
\hline Age, $y$ & $57.7 \pm 12.8$ & $56.9 \pm 12.9$ & $58.7 \pm 12.7$ & 0.142 & $57.0 \pm 12.7$ & $56.2 \pm 12.8$ & $57.8 \pm 12.7$ & 0.41 \\
\hline Sex & & & & 0.000 & & & & 0.45 \\
\hline Women & 866 & $809(93.6)$ & $65(7.4)$ & & 83 & $44(51)$ & $39(44)$ & \\
\hline Access site & & & & 0.000 & & & & 0.365 \\
\hline $\begin{array}{l}\text { Right } \\
\text { internal } \\
\text { jugular } \\
\text { vein }\end{array}$ & 1.643 & $786(91.0)$ & $857(97.8)$ & & 172 & $84(97)$ & $88(99)$ & \\
\hline Operator & & & & 0.007 & & & & 0.879 \\
\hline Professor & 314 & $134(15.5)$ & $180(20.5)$ & & 106 & $53(61)$ & $53(60)$ & \\
\hline $\begin{array}{l}\text { Fellow or } \\
\text { resident }\end{array}$ & 1.426 & $730(84.5)$ & $696(79.5)$ & & 70 & $34(39)$ & $36(40)$ & \\
\hline
\end{tabular}

Abbreviation: TICVP, totally implantable central venous port.

${ }^{\mathrm{a}}$ Values are expressed as No. (\%) or mean \pm SD.

ture site. A peel-away sheath was inserted into the jugular vein and the port catheter was introduced into the superior vena cava through a peel-away sheath. Under fluoroscopic guidance, the catheter tip was placed at the level of the cavoatrial junction. The port was not fixed to the pectoralis muscle, and the skin incision was sutured using nylon 3-0. A chest radiograph in the upright position was obtained to rule out a pneumothorax.

In the retrospective study, operators freely selected the type of TICVPs. Because men have tight subcutaneous tissue and women have loose and abundant subcutaneous tissue, most operators preferred the Humanport $®$ in men, which has a smaller chamber size, and Celsite in women, which has a larger chamber size. In the prospective study, the two TICVPs were randomly assigned.

\subsection{Management}

The TICVP was used from either the day of implantation or the next day. Before its use, patency of the TICVP was checked by blood regurgitation and infusion of normal saline without resistance. After its use, $10 \mathrm{ml}$ of a diluted heparin solution (Myengmun, Seoul, Korea) was flushed to fill the port system. When the port was not used for more than 2 weeks, the port was flushed with a diluted heparin solution every 2 weeks.

\subsection{Evaluation of Patency}

The deadline for data collection was October 2013. The primary outcome measure was the malfunction of TICVPs. The malfunction of a TICVP was identified when an infusion of fluid was resisted or the bedside regurgitation of blood was impossible. In this prospective study, we also checked the function of the TICVP using fluoroscopic images with contrast injection at both 2 weeks and 6 months after implantation to confirm the patency of the TICVPs. When a malfunction of the TICVP developed, the clinician referred the patient to the angiography suite. The function of the TICVP was checked under fluoroscopy by injecting contrast media by one author (H.C.K.). The primary patency was defined as the duration of TICVP patency without any intervention. When the TICVP was removed due to a TICVP-related bloodstream infection without malfunction of the TICVP, the patient was censored at the day of TICVP removal.

The incidence of TICVP malfunctions was reported as the rate per 1,000 catheter days. The catheter days index was defined as the total number of days of exposure to TICVPs by all patients.

\subsection{Statistical Analysis}

In the prospective study, the sample size was calculated on the basis of the following assumptions. The main end- 
point for the comparison of the two types of TICVPs was the percentage of patients with a malfunction within 6 months of insertion. According to previous studies $(4,5$, $9,10)$, the incidence of malfunction ranged from $2 \%$ to $10 \%$. We postulated that $5 \%$ of patients would suffer from a malfunction of Celsite ${ }^{\circledR}$ (B. Braun). We were also prepared to say that Humanport $®$ (Insung Medical) is significantly worse if the incidence of malfunction of Humanport $₫$ was $10 \%$ higher than that of Celsite® (6). A 5\% significance level was used with a power of $80 \%$ and a two-sided test. Under these conditions, 74 patients were required in each group and the drop-out rate would be $15 \%$. Finally, the sample size was increased to 176 patients ( 88 per group).

Fisher's exact tests were used to evaluate the association of access site, sex, TICVP, and operator. The primary patency rates of TICVPs were obtained by the Kaplan-Meier method and compared by the log-rank test. Multivariate analysis was performed by the Cox proportional hazards model. A p value $<0.05$ was considered to indicate a statistically significant difference, and statistical computer software (SPSS 19.0; IBM Corp. Released 2010. IBM SPSS Statistics for Windows, Version 19.0. Armonk, NY, USA) was used for the statistical analyses.

\section{Results}

\subsection{Retrospective Study}

A total of 1,740 TICVPs, including Celsite $\AA$ ( $\mathrm{n}=864$, 49.7\%) and Humanport $®(n=876,50.3 \%)$, were implanted from January 2010 to June 2012. Significant differences in the distributions of sex, access site, and operator were identified between the two groups $(\mathrm{P}<0.05)$ (Table 2 ).

During the follow-up period, 59 patients were referred to the angiography suite due to suspicious malfunctions of TICVPs. The causes of the TICVP malfunctions included fibrin sheath formation $(n=15)$, chamber thrombosis $(n=$ $8)$, TICVP rotation $(n=5)$, catheter migration $(n=2)$, blood clot within the catheter $(n=2)$, improper needling $(n=2)$, and no demonstrable malfunction on fluoroscopic examination $(\mathrm{n}=25)$. In all, $32(1.8 \%)$ patients had TICVP malfunctions. The incidence of TICVP malfunction was 0.058 per 1,000 catheter days. These patients were treated by manual rotation upside down $(\mathrm{n}=5)$, fibrin sheath stripping $(\mathrm{n}=$ $7)$, thrombolysis by urokinase $(n=9)$, catheter tip repositioning $(n=2)$, TICVP removal $(n=4)$, and vigorous flushing of the TICVP $(n=5)$. An upside down manual rotation was performed in patients with TICVP rotation. Fibrin sheath stripping was performed in patients with fibrin sheath formation who did not want to remove the indwelling TICVP. Thrombolysis was performed in patients with chamber thrombosis or a blood clot within the catheter. Repositioning of the catheter tip was performed in patients with a migration of the catheter by using a snare. The removal of TICVPs was performed in patients with fibrin sheath formation who did not mind the removal of the indwelling TICVP and wanted an implantation of a new TICVP. Vigorous flushing of the TICVP was performed in patients with fibrin sheath formation or a blood clot within the catheter. In patients with fibrin sheath formation, vigorous flushing of the TICVP was initially tried, and fibrin sheath stripping or removal of the TICVP and implantation of a new TICVP was performed if vigorous flushing failed to restore the function of the TICVP. Fibrin sheath stripping was successful in all seven patients, and thrombolysis by urokinase was successful in all nine patients.

Among the 32 patients with TICVP malfunctions, 22 had Celsite $®$ and 10 had Humanport $®$ (Table 3). The 32 patients with TICVP malfunctions consisted of 23 women and 9 men. Of these, 28 TICVPs were inserted via the right internal jugular vein and 4 were implanted via the left internal jugular vein. TICVP malfunctions occurred within 30 days in 15 patients, and over 90 days in 11 patients (Table 4).

The primary patency rates of the Celsite $₫$ and Humanport $®$ groups were $97.7 \%$ and $99.0 \%$ at 6 months, respectively $(\mathrm{P}=0.105)$. Univariate analysis showed significant differences for patency with sex $(\mathrm{P}=0.006)$ and TICVP type $(\mathrm{P}=0.041)$. Multivariate analysis showed that being female was a significant factor for having a poor TICVP patency rate $(\mathrm{P}=0.018)$ (Table 5$)$.

\subsection{Prospective Study}

A total of 176 TICVPs, including 87 Celsite $® ~(49.4 \%)$ and 89 Humanport $®(50.6 \%)$, were implanted in 176 patients (Table 2). There were no procedure-related complications. On the first regular follow-up, which was performed 2 weeks after implantation, all 176 patients were confirmed to have TICVPs in good working order.

During 6 months of follow-up, four patients died due to underlying diseases and nine patients were lost to follow-up. In 16 patients, TICVPs were removed due to the completion of chemotherapy $(\mathrm{n}=14)$ and TICVP-related bloodstream infections $(n=2)$. The remaining 147 patients had TICVPs with intact functions.

In two (1.1\%) patients (1 with Celsite $®$ and 1 with Humanport@), TICVP malfunctions caused by chamber thromboses occurred during the follow-up period. The incidence of TICVP malfunctions was 0.068 per 1,000 catheter days. Chamber thrombosis was treated by thrombolysis using 100,000 IU of urokinase and the TICVP function was restored. The primary patency rates of both Celsite $®$ and $\mathrm{Hu}-$ manport $®$ were $98.9 \%$ at 6 months, respectively. There was 
Table 3. Malfunctions Based on the Type of Device and Sex in the Retrospective Study

\begin{tabular}{|c|c|c|c|c|}
\hline & \multicolumn{2}{|c|}{ Type of Device } & \multicolumn{2}{|c|}{ Sex } \\
\hline & Celsite $(n=22)$ & Humanport $(n=10)$ & $\operatorname{Men}(\mathbf{n}=\mathbf{9})$ & Women $(n=23)$ \\
\hline Fibrin sheath formation $(n=15)$ & 10 & 5 & 5 & 10 \\
\hline Chamber thrombosis $(n=8)$ & 4 & 4 & 4 & 4 \\
\hline TICVP rotation $(n=5)$ & 5 & 0 & 0 & 5 \\
\hline Migration of catheter $(n=2)$ & 1 & 1 & 0 & 2 \\
\hline Blood clot within catheter $(n=2)$ & 2 & 0 & 0 & 2 \\
\hline
\end{tabular}

Abbreviation: TICVP, totally implantable central venous port.

Table 4. Time of Malfunction Based on the Type of Malfunction and Device in the Retrospective Study

\begin{tabular}{|c|c|c|c|}
\hline & Early ( $\leq 30$ Days $)$ & Late (30 - 90 Days) & Very late ( $\geq 90$ Days) \\
\hline \multicolumn{4}{|l|}{ Type of malfunction } \\
\hline Fibrin sheath formation $(n=15)$ & 4 & 4 & 7 \\
\hline Chamber thrombosis $(n=8)$ & 5 & 0 & 3 \\
\hline TICVP rotation $(n=5)$ & 3 & 1 & 1 \\
\hline Blood clot within the catheter $(n=2)$ & 1 & 1 & 0 \\
\hline \multicolumn{4}{|l|}{ Device } \\
\hline Celsite $(\mathbf{n}=\mathbf{2 2})$ & 10 & 4 & 8 \\
\hline Humanport $(n=10)$ & 5 & 2 & 3 \\
\hline
\end{tabular}

Table 5. Univariate and Multivariate Analysis for Primary Patency Rate in the Retrospective Study

\begin{tabular}{|c|c|c|c|c|c|c|}
\hline & \multicolumn{3}{|c|}{ Univariate Analysis } & \multicolumn{3}{|c|}{ Multivariate Analysis } \\
\hline & Hazard Ratio & 95\% CI & PValue & Hazard Ratio & 95\% CI & P Value \\
\hline Female & 3.08 & $1.38,6.86$ & 0.006 & 5.06 & $1.32,19.46$ & 0.018 \\
\hline Left internal jugular vein & 2.35 & $0.82,6.68$ & 0.108 & - & - & - \\
\hline Operator (fellow or resident) & 1.23 & $0.53,2.86$ & 0.619 & - & - & - \\
\hline
\end{tabular}

Abbreviation: CI, confidence interval.

no significant factor related with TICVP malfunctions as determined by univariate analysis.

\section{Discussion}

TICVP implantations have become tremendously popular, especially for the care of oncologic patients. The placement of the TICVP itself is a relatively simple procedure. However, the reported incidence and types of complications related to the implantation have been variable in the literature. This may be partly attributed to the diversity in the access vessel (jugular vein, subclavian vein, and arm vein), the implantation site (arm vs. chest), implantation technique (surgical vs. radiological), and the TICVP devices (8-15).

Complications related with TICVPs can be categorized into procedural, infectious, and mechanical complications. Catheter malfunction, a type of mechanical complication, has the tendency to occur later, several weeks to months after implantation of TICVPs. The reported incidences of catheter malfunction range from $0 \%$ to $47 \%$ because the definition of a catheter malfunction is not uni- 
form (8). Yet, about half of them reported that catheter malfunction rates were less than $3 \%$ (8). The catheter malfunction rate in our retrospective study (1.8\%) is comparable with that reported in previous studies.

Catheter malfunctions may be caused by fibrin sheath formation, thrombosis of the chamber and catheter, rotation of the TICVPs, and catheter migration. Thus, the first step in the management of a TICVP malfunction is to elucidate the cause of the malfunction. Fibrin sheath formations were the most common cause (47\%, 15 out of 32 ) of catheter malfunction in our retrospective study. These are known to manifest as a persistent withdrawal occlusion despite having an intact injection of fluid. Endovascular stripping using a snare device is commonly performed to break down the fibrin sheath, but recurrence of the fibrin sheath is also common (16-18). In our study, fibrin sheath stripping was performed in 7 out of 15 patients with fibrin sheath formations. Fibrin sheath stripping was preferred early in the study period. However, we tried to reduce catheter dysfunction by vigorous flushing of the TICVPs later in the study period because we experienced some cases of recurrent fibrin sheath formation even after performing endovascular stripping. Furthermore, vigorous flushing of the TICVPs was able to increase the infusion rate high enough to receive chemotherapy. We speculate that vigorous flushing may be able to form a crack in the fibrin sheath resulting in an increased infusion rate.

Thrombosis within the chamber and catheter is also a common cause of catheter malfunction. Thrombosis of the chamber may be caused by a regurgitation of blood into the chamber during chemotherapy. Additionally, if the catheter tip is stuck in tributaries, such as the azygos vein or the internal mammary vein, thrombosis of the catheter may occur. If the TICVP is inserted via the left internal jugular vein, and the catheter is slightly retracted, the end of catheter tip may be pressed against the lateral wall of the superior vena cava causing occlusion of the catheter. Thrombosis within the chamber and catheter can be resolved by thrombolysis using urokinase (5).

Rotation of the TICVP is an infrequent situation and fixation of the reservoir port to the chest wall for prevention of this complication is not routinely performed by many radiologists. The incidence of rotation may increase if the pocket is too large or if the subcutaneous fat tissue is very loose. Rotation of the TICVP is easily diagnosed on fluoroscopy and can be simply managed by manually rotating the reservoir port upside down.

In our institution, we prefer inserting Celsite $®$ in female patients while using Humanport@ in male patients because the size of the reservoir port is larger in the Celsite ${ }^{\circ}$. As women commonly have loose subcutaneous fat tissue, creating a large subcutaneous pocket is not diffi- cult. Moreover, small TICVPs tend to rotate and may be difficult to palpate in women with abundant subcutaneous fat tissue. In contrast, men commonly have dense subcutaneous tissue rendering the creation of a large pocket difficult. Thus, Celsite $₫$ and Humanport $₫$ were mostly implanted in women and men, respectively.

In our retrospective study, multivariate analysis showed that malfunctions of TICVPs were commonly associated with female patients. There are several explanations for this; first, TICVP rotation only occurred in female patients. Since women have loose subcutaneous tissue, there would have been a greater chance for TICVPs to rotate if an overly large pocket was created. Second, the left internal jugular vein was chosen for venous access in female patients who had received surgery for right breast cancer. The TICVP catheter placed in the left internal jugular vein has a greater chance of being occluded because the catheter can be wedged against the lateral wall of the superior vena cava. However, this study failed to show a statistically significant high incidence of malfunction in TICVPs placed via the left internal jugular vein. Third, catheter tip migration can be exaggerated in female patients with large breasts. In the upright position, large breasts can sag considerably, which results in an upward migration of the catheter tip.

In our prospective study, having a small study population was the basic limitation, and TICVP malfunctions occurred in only two patients. Thus, statistical analysis failed to reveal significant factors influencing the incidence of malfunctioning TICVPs.

There are several limitations in our study. First, we cannot exclude the possibility of missing some complications since they were assessed based on medical records or follow-up imaging. For instance, minimal tip occlusion may have been resolved simply by meticulously flushing saline at the bedside. Additionally, a small amount of hematoma or minor wound dehiscence not requiring revision could have occurred without us knowing. This may have resulted in an underestimation of the total complication rate. Nevertheless, these complications are minor and not of much clinical importance in terms of patient outcomes or costs. Second, fibrin sheath formation was common in female patients in this study, but the exact reason or postulation could not be clarified. Third, we did not evaluate the type of malignancy, patients' baseline conditions, chemotherapy drugs, and the number of chemotherapy cycles in the analysis of influencing factors on TICVP malfunctions.

In conclusion, catheter malfunctions of TICVPs were more common in female patients. The incidence of TICVP malfunctions is not different between the two devices (Celsite $($ vs Humanport () in this study. 


\section{Acknowledgments}

None declared.

\section{Footnotes}

Authors' Contribution: Study concept and design: HyoCheol Kim, Saebeom Hur; acquisition of data: Hyo-Cheol Kim, Hur, Hoyong Jeon; analysis and interpretation of data: Hyo-Cheol Kim, Saebeom Hur, Hoyong Jeon; drafting of the manuscript: Hyo-Cheol Kim, Hoyong Jeon; critical revision of the manuscript for important intellectual content: HyoCheol Kim, Saebeom Hur, Hoyong Jeon; statistical analysis: Hyo-Cheol Kim, Saebeom Hur; administrative, technical, and material support: Saebeom Hur, Hoyong Jeon; study supervision: Hyo-Cheol Kim.

Funding/Support: This work was supported by grants from the Korea Medical devices industrial cooperative association (KMDICA), funded by the Small and medium business administration (SMBA).

Conflict of Interests: There are no conflicts of interest.

\section{References}

1. Dede D, Akmangit I, Yildirim ZN, Sanverdi E, Sayin B. Ultrasonography and fluoroscopy-guided insertion of chest ports. EurJ Surg Oncol. 2008;34(12):1340-3. doi:10.1016/j.ejso.2007.12.001. [PubMed: 18191364].

2. Di Carlo I, Pulvirenti E, Mannino M, Toro A. Increased use of percutaneous technique for totally implantable venous access devices. Is it real progress? A 27-year comprehensive review on early complications. Ann Surg Oncol. 2010;17(6):1649-56. doi: 10.1245/s10434-0101005-4. [PubMed: 20204533].

3. Sakamoto N, Arai Y, Takeuchi Y, Takahashi M, Tsurusaki M, Sugimuta K. Ultrasound-Guided Radiological Placement of Central Venous Port via the Subclavian Vein: A Retrospective Analysis of 500 Cases at a Single Institute. Cardiovasc Intervent Radiol. 2010;33(5):989-94. doi: 10.1007/s00270-010-9841-y. [PubMed: 20390274].

4. Teichgraber UK, Kausche S, Nagel SN, Gebauer B. Outcome analysis in 3,160 implantations of radiologically guided placements of totally implantable central venous port systems. Eur Radiol. 2011;21(6):122432. doi: 10.1007/s00330-010-2045-7. [PubMed: 21207035].

5. Ahn SJ, Kim HC, Chung JW, An SB, Yin YH, Jae HJ, et al. Ultrasound and fluoroscopy-guided placement of central venous ports via internal jugular vein: retrospective analysis of 1254 port implantations at a single center. Korean J Radiol. 2012;13(3):314-23. doi: 10.3348/kjr.2012.13.3.314. [PubMed: 22563269].
6. Goltz JP, Janssen H, Petritsch B, Kickuth R. Femoral placement of totally implantable venous power ports as an alternative implantation site for patients with central vein occlusions. Support Care Cancer. 2014;22(2):383-7. doi: 10.1007/s00520-013-1984-3. [PubMed: 24061782].

7. Moureau N, Poole S, Murdock MA, Gray SM, Semba CP. Central venous catheters in home infusion care: outcomes analysis in 50,470 patients. J Vasc Interv Radiol. 2002;13(10):1009-16. [PubMed: 12397122].

8. Goossens GA, Stas M, Jerome M, Moons P. Systematic review: malfunction of totally implantable venous access devices in cancer patients. Support Care Cancer. 2011;19(7):883-98. doi: 10.1007/s00520-011-1171-3. [PubMed: 21556721].

9. Bassi KK, Giri AK, Pattanayak M, Abraham SW, Pandey KK. Totally implantable venous access ports: retrospective review of long-term complications in 81 patients. Indian J Cancer. 2012;49(1):114-8. doi: 10.4103/0019-509X.98934. [PubMed: 22842178].

10. Goltz JP, Petritsch B, Thurner A, Hahn D, Kickuth R. Complications after percutaneous placement of totally implantable venous access ports in the forearm. Clin Radiol. 2012;67(11):1101-7. doi: 10.1016/j.crad.2012.03.007. [PubMed: 22583951].

11. Toure A, Vanhems P, Lombard-Bohas C, Cassier P, Pere-Verge D, Souquet JC, et al. Totally implantable central venous access port infections in patients with digestive cancer: incidence and risk factors. Am J Infect Control. 2012;40(10):935-9. doi: 10.1016/j.ajic.2012.01.024. [PubMed: 22633131].

12. Subramaniam A, Kim KH, Bryant SA, Kimball KJ, Huh WK, Straughn JM, et al. Incidence of mechanical malfunction in low-profile subcutaneous implantable venous access devices in patients receiving chemotherapy for gynecologic malignancies. Gynecol Oncol. 2011;123(1):54-7. doi: 10.1016/j.ygyno.2011.06.012. [PubMed: 21742372].

13. Plumhans C, Mahnken AH, Ocklenburg C, Keil S, Behrendt FF, Gunther RW, et al. Jugular versus subclavian totally implantable access ports: catheter position, complications and intrainterventional pain perception.EurJRadiol. 2011;79(3):338-42. doi: 10.1016/j.ejrad.2009.12.010. [PubMed: 20227211].

14. Ruesch S, Walder B, Tramer MR. Complications of central venous catheters: internal jugular versus subclavian access-a systematic review. Crit Care Med. 2002;30(2):454-60. [PubMed: 11889329].

15. Moeinipour AA, Amouzeshi A, Joudi M, Fathi M, Jahanbakhsh S, Hafez $S$, et al. A rare central venous catheter malposition: a case report. Anesth Pain Med. 2014;4(1):ee16049. doi: 10.5812/aapm.16049. [PubMed: 24660160].

16. Gray RJ, Levitin A, Buck D, Brown LC, Sparling YH, Jablonski KA, et al. Percutaneous fibrin sheath stripping versus transcatheter urokinase infusion for malfunctioning well-positioned tunneled central venous dialysis catheters: a prospective, randomized trial. J Vasc Interv Radiol. 2000;11(9):1121-9. [PubMed: 11041467].

17. Merport M, Murphy TP, Egglin TK, Dubel GJ. Fibrin sheath stripping versus catheter exchange for the treatment of failed tunneled hemodialysis catheters: randomized clinical trial.J Vasc Interv Radiol. 2000;11(9):1115-20. [PubMed: 11041466].

18. Heye S, Maleux G, Goossens GA, Vaninbroukx J, Jerome M, Stas M. Feasibility and safety of endovascular stripping of totally implantable venous access devices. Cardiovasc Intervent Radiol. 2012;35(3):607-12. doi: 10.1007/s00270-011-0158-2. [PubMed: 21479744]. 